\title{
4
}

\section{The Pathophysiological Implications of TRP Channels in Cardiac Arrhythmia}

\author{
Ryuji Inoue, Duan Yubin, Hu Yaopeng and Jun Ichikawa \\ Department of Physiology, Fukuoka University School of Medicine
}

Japan

\section{Introduction}

The cardiac arrhythmia is a common cause of morbidity and mortality in the present world, especially in developed countries. The etiology of cardiac arrhythmia is quite broad involving both hereditary and secondary backgrounds. An increasing number of rare but lethal arrhythmogenic mutations have been identified by genome-wide association assays in genes associated with cardiac excitation, conduction and morphogenesis. Such well-characterized examples include causative mutations in voltagedependent $\mathrm{Na}^{+}, \mathrm{Ca}^{2+}$ or $\mathrm{K}^{+}$channel $\left(\mathrm{Na}_{\mathrm{v}}, \mathrm{Ca}_{\mathrm{v}}, \mathrm{K}_{\mathrm{v}}\right)$ genes for the prolongation of QT interval which sometimes result in premature sudden death and may act as predisposing factors to drug-induced arrhythmia (Chen et al., 1998; Roden, 2004; Saenen \& Vrints, 2008; Towbin \& Vatta, 2001; Zareba et al., 2004). Furthermore, some of heart malformations (e.g. atrial septal defect) and idiopathic cardiomyopathy (e.g. dilated cardiomyopathy) with symptoms of arrhythmias have also proved to have some genetic linkage to impaired impulse conduction (Benson et al., 1999; Bonne, et al.,2001; Schott et al., 1998). However, much more prevalent are rhythm disturbances and conduction failures occurring in 'remodeling' hearts which progressively undergo structural and electrical changes in prolonged metabolically and mechanically stressed states, e.g. chronic heart failure and myocardial infarction (Nattel, 2007; Olson, 2005). The well-known consequences of cardiac remodeling are; altered expression and gating properties of ion channels shaping the action potential and generating pace-making activities; reduced electrical coupling which leads to aberrant conduction of excitation. These changes are thought to work as the 'substrates' increasing the risk of lethal cardiac arrhythmia (Janse, 2004; Nattel, 2007). It has also been known that abnormal handling of intracellular $\mathrm{Ca}^{2+}$ occurring in the remodeled heart may cause spontaneous membrane depolarizations triggering ectopic excitations (Dobrev, 2010; Janse, 2004; Nattel, 2007). However, the available knowledge is still limited largely to ion channels/transporters/pumps whose roles in the cardiac excitation-contraction cycle have relatively been well established.

The transient receptor potential (TRP) channels constitute a newly-emerging non-selective cation channel (NSCC) superfamily activated by a plethora of physico-chemical stimuli other than voltage change. Because of this unique activation profile as well as the ability to permeate $\mathrm{Ca}^{2+}$ (except for TRPM4/TRPM5), TRP channels have attracted great attention as promising candidate molecules elucidating a variety of biological functions and disorders 
associated with slow sustained $\mathrm{Ca}^{2+}$ influx initiated by neurohormonal factors, pheromones, mechanical (membrane stretch/bending, osmotic change, shear force etc.) and thermal (from cold through cool and warm to heat) stresses, noxious stimuli (acid, respiratory irritants and toxicants) and many gustatory and pungent/cooling agents (camphor, citral, capsaicin, eucalyptol, icilin, menthol, allicin, mustard oil, sweet, umami and bitter tastants etc.) (Holzer, 2011; Vay et al., 2011; Wu et al., 2010). In the cardiovascular system, recent investigations have revealed pathophysiological implications of TRP channels in vasospasm, hypertension, occlusive vascular diseases, cardiac hypertrophy, cardiomyopathy and cardiac arrhythmia (Dietrich et al., 2010; Inoue et al, 2009b; Watanabe et al., 2008). Especially, as will be described below, involvement of some TRP channels in abnormal intracellular $\mathrm{Ca}^{2+}$ handling and increased responses to mechanical and noxious stresses may make them particularly relevant to the pathogenesis of acquired cardiac arrhythmias tightly associated with cardiac hypertrophy and failure, myocardial infarction and atrial fibrillation (Nattel, 2007; Ter Keurs \& Boyden, 2007).

This chapter will deal with the arrhythmogenic potential of several TRP isoforms identified in the cardiovascular system, with brief introduction to the general concepts of cardiac arrhythmia and its connection to cardiac diseases and with several examples in which the roles of TRP channels have been established or suggested.

\section{Factors contributing to cardiac arrhythmia}

Cardiac arrhythmia is the abnormality of cardiac rhythm, the highly coordinated and integrated electrophysiological behavior of multiple ion channels/transporters/exchangers residing in tens of billions of myocytes and non-myoctes consisting of the heart. Clinically, cardiac arrhythmia can be defined as any anomalous excitations out of normal sinus control, and is conventionally classified into bradyarrhythmia ( $<50$ beats per minute) and tachyarrhythmia $(>100)$. Faulty or abnormal excitation of sinus node and various extents of conduction blocks mainly explain the former. In contrast, ectopic excitations occurring outside the sinus node (triggered activity, ectopic automaticity) and perpetuation of spiral/scroll waves rotating around a central core/filament (reentry) are thought to contribute to the latter. Although the mechanism remains still incompletely understood, shortened refractoriness, slowed and anisotropic conduction facilitate the occurrence of reentry (Jalife, 2000). Thus, altered expression or activities of ion channels contributing to the upstroke $\left(\mathrm{Na}_{\mathrm{v}}\right)$ and repolarization of action potential $\left(\mathrm{K}_{\mathrm{v}}\right)$ as well as those determining the conduction velocity and cell-to-cell coupling $\left[\mathrm{Na}_{\mathrm{v}}\right.$ and connexins (Cx), respectively] are involved in the reentrant mechanism.

Ectopic excitations result from premature depolarizations before the next normal excitation arrives. Early afterdepolarization (EAD) occurs before the repolarization of action potential completely terminates, thereby prolonging it and evoking premature action potentials due to re-opening of $\mathrm{Na}_{\mathrm{v}}$ and/or $\mathrm{Ca}_{\mathrm{v}}$ channels. This is a mechanistic background for the initiation of a specific form of polymorphic ventricular arrhythmias (Torsades de pointes) observed in both congenital and drug-induced Long QT syndromes; the function of 'repolarization reserve', i.e. $\mathrm{K}_{\mathrm{v}}$ channels, is compromised, or residual activity of $\mathrm{Na}_{\mathrm{v}}$ channel sustains because of its incomplete inactivation (Roberts \& Gollob, 2010).

Delayed afterdepolarization (DAD) is thought to reflect the generation of transient inward currents $\left(\mathrm{I}_{\mathrm{ti}}\right)$ activated by diastolic $\mathrm{Ca}^{2+}$ release from the sarcoplasmic reticulum (SR) of 
myocytes (Venetucci et al., 2008). If the magnitude of DAD exceeds the threshold of $\mathrm{Na}_{\mathrm{v}}$ channel activation, an extrasystolic discharge of action potentials occurs. Sustained discharges from one or more foci may propagate around to cause tachyarrhythmias (focal excitation). In ventricular myocytes from rabbit failing heart which shows spontaneous ventricular tachyarrhythima, $\mathrm{I}_{\mathrm{ti}}$ has been ascribed exclusively to enhanced forward-mode $\mathrm{Na}^{+} / \mathrm{Ca}^{2+}$ exchanger type 1 (NCX1) current (Pogwizd et al., 2001; Pogwizd \& Bers, 2004). However, there is evidence that implicates $\mathrm{Ca}^{2+}$-dependent $\mathrm{Cl}^{-}$and nonselective cationic conductances in the genesis of DAD (Han \& Ferrier, 1992; Hill et al., 1988; Kass et a., 1978; Laflamme \& Becker, 1996; Wu \& Anderson, 2000). The mechanism underlying the diastolic $\mathrm{Ca}^{2+}$ release is likely to reflect $\mathrm{Ca}^{2+}$ overload into the sarcoplasmic reticulum (SR) caused by a net increase in $\mathrm{Ca}^{2+}$ uptake into the SR (increased $\mathrm{Ca}^{2+}$ influx and SRECA2a $\mathrm{Ca}^{2+}$-ATPase activity), or the dysfunction of ryanodine type 2 receptor (RyR2) which may, especially when intensively phosphorylated by protein kinase A (Wehrens et al., 2003) or $\mathrm{Ca}^{2+} /$ calmodulin-dependent kinase II (Ai et al, 2005), causes a diastolic $\mathrm{Ca}^{2+}$ leak from the SR (Bers, 2006). Thus, under excessive sympathetic activities (hard exercise, mental stress, chronic heart diseases) or upon the application of drugs increasing the cAMP level (caffeine, catecholamines, phosphodiesterase inhibitors) or $\left[\mathrm{Na}^{+}\right]_{\mathrm{i}}$ (digitalis) in cardiomyocytes which increase $\mathrm{Ca}^{2+}$ loading into the SR, the occurrence of DAD and resultant tachyarrhythmias may be greatly enhanced (Pogwizd, 2003; Sipido, 2007; Venetucci, 2008). In addition, in some pathological settings such as unphysiologically decreased extracellular $\mathrm{K}^{+}$level and excessive sympathetic activity, ectopic automaticity, particularly in the Purkinje fiber, can also be abnormally increased to cause tachyarrhythmias (Osadchii, 2010).

Clinical significance of mechanical loading in inducing arrhythmia has been well recognized (Dean \& Lab, 1989). It is widely accepted that both acute and chronic stretch of myocardial tissue significantly affects its electrophysiological properties to increase the propensity for arrhythmia (Janse, 2003; Ravens, 2003). Experimentally, a transient diastolic stretch of isolated left ventricle was shown to induce ventricular arrhythmia which was inhibited by micromolar Gd ${ }^{3+}$ (Hansen et al. 1991; Stancy et al, 1992). Atrial fibrillation elicited by an acute increase in intra-atrial pressure in isolated rabbit hearts was also found effectively blocked by MSCC blockers, Gd ${ }^{3+}$ and a Tarantula toxin GsMTx-4 (Franz and Bode, 2003; Suchyna, 2000). At the single cell level, Kamkin et al. (2000a) demonstrated that direct stretch of a ventricular myocyte could cause membrane depolarization and prolongation of action potential resembling EAD, which, at extensive stretch, led to an extrasystolic depolarization. This stretch-induced depolarization was attributed to the activation of $\mathrm{Gd}^{3+}$-sensitive mechanosensitive NSCCs (MSCCs) (Hamill \& Martinac, 2001; Inoue et al., 2009b). The stretch sensitivity of MSCCs was significantly enhanced in hypertrophied cardiomyocytes with increased susceptibility to stretch-induced arrhythmia (Kamkin et al., 2000a). Considering that the heart is continuously subjected to hemodynamic stresses and deformation due to contraction, mechanical stresses may play a significant role in the causality and severity of arrhythmia, particularly under pressure- and volume-overloaded conditions.

\section{Connection of cardiac diseases to cardiac remodeling and arrhythmia}

The cardiac remodeling can be defined as the restructuring and reactivation of differentiated cardiac tissues comprised of myocytic and non-myocytic populations, and is initiated and 
progressed by a complex interplay of genetic, environmental and aging factors (Cohn, et al., 2000; Fedak, et al., 2005; Swynghedauw, 1999). Chronic heart failure, myocardial infarction and atrial fibrillation (AF) are three common pathological states accompanying the remodeling process with arrhythmic changes; in which excessively activated sympathetic nervous and renin-angiotensin-aldosterone systems, increased generation of inflammatory cytokines and reactive oxygen/nitrogen species, and sustained mechanical stresses likely play active roles. The remodeling process is initially 'adaptive' to compensate the impaired pumping function, but gradually becomes 'maladaptive' with disturbances in rhythm formation and conduction as common clinical complications.

The key consequences of cardiac remodeling associated with the appearance of arrhythmia include both structural and electrical alterations. Enhanced collagen synthesis promotes the fibrotic replacement of damaged myocardial tissues thereby increasing the electrical heterogeneity. Altered expression and activities of ion channels, transporters and exchangers also bring about significant changes in the shape of action potential and its conduction properties as well as induce the susceptibility to premature excitations (Nattel, et al., 2007; Janse, 2004).

In chronic heart failure, the major electrophysiological changes are pronounced prolongation of action potential which often accompanies EAD-like membrane oscillations. These changes likely occur through decreased expression or activity of transient outward current $\left(\mathrm{I}_{\mathrm{to}} ; \mathrm{K}_{\mathrm{v}} 4,3\right)$ and voltage-dependent $\mathrm{K}^{+}$channels forming the repolarization phase of action potential $\left(\mathrm{I}_{\mathrm{Kr}}, \mathrm{I}_{\mathrm{Ks}}\right)$ (Bers, 2006; Janse, 2004; Nattel, et al.,2007; Ravens, 2010). The reduced inward rectifying $\mathrm{K}^{+}$current $\left(\mathrm{I}_{\mathrm{K} 1}\right)$ may also destabilize the membrane (i.e. increases the diastolic membrane resistance) and thereby enhance extrasystolic depolarizing responses (DAD) (Nattel, et al., 2007; Pogwitz et al, 2001). Furthermore, upregulation of hyperpolarization-activated current $\left(\mathrm{I}_{\mathrm{f}}\right)$ and its mRNA (HCN2/4) (Cerbai, 1994; FernandezVelasco et al., 2003) and reduced expression of gap junction channel (Cx43; Dupont et al, 2001) have been reported to contribute to abnormally enhanced automaticity and impaired conduction, respectively. However, more notable changes observed in failing heart are abnormalities in intracellular $\mathrm{Ca}^{2+}$ handling (Bers, 2006; Janse, 2004). Despite a reduction in the SR $\mathrm{Ca}^{2+}$ content due to decreased expression of SERCA2a, the propensity for triggered activity based on DAD is enhanced. This likely reflects the other two major changes in $\mathrm{Ca}^{2+}$ handling, i.e. (1) the increased $\mathrm{Ca}^{2+}$ sensitivity of RyR2 under intensive phosphorylation by protein kinase A (however controversial now; Wehrens et al, 2003) or $\mathrm{Ca}^{2+} / \mathrm{calmodulin}^{2}$ kinase II (Ai et al, 2005) which causes diastolic $\mathrm{Ca}^{2+}$ leak from the SR, and (2) upregulation of $\mathrm{Na}^{+} / \mathrm{Ca}^{2+}$ exchanger (NCX1) protein which can carry depolarizing inward currents in the diastole. It has been suggested that increased $\beta$-adrenergic drive, which is prominent in chronic heart failure, may greatly facilitate the occurrence of DAD by increasing the $\mathrm{Ca}^{2+}$ content in the SR above the threshold of spontaneous $\mathrm{Ca}^{2+}$ release (Bers, 2006; Pogwizd, 2003).

Myocardial infarction is initiated by a sudden cessation of blood supply to heart tissues (i.e. myocardial ischemia), most frequently by thrombotic obstruction of coronary arteries. The time course of ischemic changes in the heart is variable and complex, and can mechanistically be distinguished between early and late acute phases, and subsequent postinfarction period vulnerable to structural and electrical remodeling (Clements-Jewery et al., 2005; Janse \& Wit, 1989; Nattel et al., 2007). In acute phases, rapid depletion of intracellular ATP and accumulation of intracellular ADP, extracellular $\mathrm{K}^{+}$and lactate 
occur because of anaerobic glycolysis, and loss of intracellular $\mathrm{K}^{+}$and intracellular acidosis follows. The extracellular accumulation of $\mathrm{K}^{+}$leads to the depolarization of myocyte membrane that attenuates the amplitude and upstroke velocity of action potential (facilitated $\mathrm{Na}_{\mathrm{v}}$ inactivation) and the shortening of action potential duration (due to enhanced $K_{v}$ activities) or refractoriness. Simultaneously, intercellular accumulation and release of many biochemical substances occurs including catecholamines, ATP, lysophosphatidylcholine, cytokines (e.g., TNFa), reactive oxygen species (ROS), and platelet-activating factors (Clements-Jewery et al., 2005; de Jong \& Dekker, 2010). All these possess arrhythmogenic potential to induce ventricular premature excitations (DAD, EAD) and reentry. In postinfarction period, down-regulation of $\mathrm{K}^{+}$channels $\left(\mathrm{I}_{\mathrm{to}}, \mathrm{I}_{\mathrm{Ks}}, \mathrm{I}_{\mathrm{Kr}}, \mathrm{I}_{\mathrm{K} 1}\right.$ ) occurs in border-zones adjacent to infarct areas which impairs the repolarization of action potential leading to EAD, and altered intracellular $\mathrm{Ca}^{2+}$ handling facilitates spontaneous subcellular $\mathrm{Ca}^{2+}$ release events that can trigger arrhythmic episodes (Nattel, et al., 2007).

Atrial fibrillation (AF) is a common supraventicular tachyarrhythmia with rapid and highly irregular firing, being closely associated with aging and cardiovascular diseases such as heart failure, myocardial infarction, valvular diseases and hypertension (Nattel et al, 2007; Ravens, 2010). AF per se is thought to serve as an arrhythmogenic remodeling process, because the occurrence of AF itself progressively aggravates electrophysiological features and facilitates fibrotic changes of atrial tissues in favor of more frequent and sustained occurrences. This clinical feature is described "AF begets AF" and experimentally confirmed by the finding that rapid atrial pacing causes significant shortening of atrial refractoriness and persistent AF (Wijffels, et al. 1995). The major arrhythmogenic changes found for AF are marked shortening of action potential duration which reduces the refractoriness and increases the susceptibility to reentry (Nattel et al, 2007; Ravens, 2010). In AF, this change is combined with abnormal $\mathrm{Ca}^{2+}$ handling with increased $\mathrm{Ca}^{2+}$ release from the $\mathrm{SR}$ and augmented NCX1 expression which facilitates ectopic premature depolarizations (i.e. DAD) that serve as a trigger to initiate the reentry (Dobrev, 2010). Both reduced/increased or unchanged expression of gap-junction channels have been reported, but their increased regional heterogeneity may contribute to various extents of conduction failure and reentry (Nattel, et al., 2007).

\section{TRP channels and cardiac arrhythmia}

The above considerations strongly suggest that, although alterations in the genesis and conduction properties of action potential are undoubtedly of central importance, other factors, e.g. $\mathrm{Ca}^{2+}$ overload, increased stretch sensitivity and noxious stimuli generated in ischemia/reperfusion, may also play a vital role in arrhythmogenicity. It is also possible that structural remodeling (necrotic/apoptotic and fibrotic changes) may contribute to the electrical heterogeneity of the myocardium which may act as the pro-arrhythmic substrates for altered conduction and reentry. As described above, $\mathrm{Ca}^{2+}-$ and stretch-sensitivities, nociception as well as association to remodeling are the hallmark features of TRP channel members (Inoue et al., 2009b; Nishida \& Kurose, 2008; Watanabe et al., 2008; Wu et al, 2010; Vay et al., 2011). Therefore, in the following, we would like to discuss about the pathophysiological relevance of several TRP isoforms particularly in these aspects of acquired arrhythmogenicity (see Table 1). 


\begin{tabular}{|c|c|c|c|c|}
\hline & Intrinsic activator/modulator & $\begin{array}{c}\text { possible arrhythmogenic } \\
\text { mechanisms }\end{array}$ & $\begin{array}{l}\text { chemical } \\
\text { agonists }\end{array}$ & inhibitors \\
\hline \multicolumn{5}{|c|}{ Cardiomyocyte } \\
\hline TRPC1 & $\begin{array}{l}\text { store depletion, stretch?, GPCR } \\
\text { stimulation (TRPC1/TRPC4 or } \\
\text { C5), } \mathrm{Ca}^{2+} / \mathrm{CaM}\end{array}$ & $\begin{array}{l}\text { strecth-induced } \\
\text { EAD/DAD in } \\
\text { hypertrophy? }\end{array}$ & & $\begin{array}{l}\mathrm{Gd}^{3+}, \mathrm{SKF}, \\
\text { GsMTX-4? }\end{array}$ \\
\hline TRPC3 & $\begin{array}{l}\text { const-act., store depletion, GPCR } \\
\text { stimulation, BDNF, DAG, } \\
\text { oxidative stress (TRPC3/C4), } \\
\mathrm{Ca}^{2+} / \mathrm{CaM}, \mathrm{PKC}, \mathrm{PKG}, \mathrm{Src}\end{array}$ & $\begin{array}{l}\text { oxidative stress? and other } \\
\text { mediators (ATP, UTP) } \\
\text { during } \\
\text { ischemia/reperfusion }\end{array}$ & & $\begin{array}{l}\mathrm{Gd}^{3+}, \mathrm{La}^{3+}, \mathrm{SKF}, \\
2-\mathrm{APB}, \text { flufenamate, } \\
\text { Pyr-3 }\end{array}$ \\
\hline TRPC5 & $\begin{array}{l}\text { const-act, store depletion, GPCR } \\
\text { stimulation, LPC } 、 S 1 P 、 E G F, \\
\text { neurosteroids, oxdized } \\
\text { phospholipids, } \mathrm{Ca}^{2+} / \mathrm{CaM,} \\
\mathrm{PGE}_{2} 、 \text { S-nitrosylation, } \\
\text { thioredoxin, oxidative stress } \\
\left(\mathrm{H}_{2} \mathrm{O}_{2}\right)\end{array}$ & $\begin{array}{l}\text { possible relation to } \\
\text { ischemia/oxidative stress } \\
\text { in failing heart }\end{array}$ & $\begin{array}{l}\mathrm{Gd}^{3+}, \mathrm{SKF} \\
\text { GsMTX-4? }\end{array}$ & $\begin{array}{l}\mathrm{Gd}^{3+}, \mathrm{La}^{3+} \text { (high), } \\
\text { SKF, 2-APB, BTP-2, } \\
\text { ML-7, ML-9, } \\
\text { propfol, halothane, } \\
\text { chloroform }\end{array}$ \\
\hline TRPC6 & $\begin{array}{l}\text { store depletion, stretch?, GPCR } \\
\text { stimulation, GF, DAG, 20-HETE, } \\
\mathrm{PIP}_{3} / \mathrm{PIP}_{2}, \mathrm{Ca}^{2+} / \mathrm{CaM}, \mathrm{CaMKII}, \\
\mathrm{PKC}_{\text {, PKG } 、 \text { Fyn }}\end{array}$ & $\begin{array}{l}\text { stretch-inudced } \\
\text { EAD/DAD in } \\
\text { hypertrophy? }\end{array}$ & flufenamate & $\begin{array}{l}\mathrm{Gd}^{3+}, \mathrm{La}^{3+}, \mathrm{SKF}, \\
\text { 2-APB, ML-9, ML-7, } \\
\text { GsMTX-4? }\end{array}$ \\
\hline TRPM2 & $\begin{array}{l}\left.\text { oxidative stress (e.g. } \mathrm{H}_{2} \mathrm{O}_{2}\right) \\
\text { ADPR, cADPR, NAADP, AMP, } \\
{\left[\mathrm{Ca}^{2+}\right] \mathrm{i}, \mathrm{pH}}\end{array}$ & \multicolumn{2}{|l|}{$\begin{array}{l}\text { oxidative stress in } \\
\text { ischemia/reperfusion? }\end{array}$} & $\begin{array}{l}\text { flufenamate, } \\
\text { ACA, 2-APB }\end{array}$ \\
\hline TRPM4 & $\begin{array}{l}{\left[\mathrm{Ca}^{2+}\right] \text { i, GPCR stimulation, } \mathrm{PIP}_{2},} \\
\mathrm{MgATP}, \mathrm{ATP}, \mathrm{ADP}, \mathrm{AMP}, \\
\text { voltage, PKC } 、 \mathrm{CaM} \text {, spermine, }\end{array}$ & $\begin{array}{l}\text { familial conduction block } \\
\text { (PFHBI, ICCD), stretch- } \\
\text { inudced EAD/DAD?, QT- } \\
\text { elongation in hypertrophy, } \\
\text { DAD in AF? }\end{array}$ & $\begin{array}{l}\text { decavanadate, } \\
\text { BTP-2 }\end{array}$ & $\begin{array}{l}\mathrm{Gd}^{3+}, \text { flufenamate, } \\
\text { clotrimazol, 9-PA }\end{array}$ \\
\hline TRPC6 & see above & $\begin{array}{l}\text { cardiac fibroblast } \\
\text { anti-fibrogenesis }\end{array}$ & see above & see above \\
\hline TRPM7 & $\begin{array}{l}\text { const-act, GPCR stimulation, } \\
{\left[\mathrm{Mg}^{2+}\right]_{\mathrm{i}}, \mathrm{MgATP}, \mathrm{ATP}, \mathrm{CTP}, \mathrm{GTP},} \\
\mathrm{UTP}, \mathrm{pH}, \mathrm{PIP}_{2}, \mathrm{cAMP}, \mathrm{PKA}, \\
\text { spermine, }\end{array}$ & fibrogenesis in $\mathrm{AF}$ & 2-APB (high) & $\begin{array}{l}\mathrm{Gd}^{3+}, \mathrm{SKF}, 2-\mathrm{APB} \\
\text { (low), LOE908, }\end{array}$ \\
\hline TRPA1 & $\begin{array}{l}\text { cold }\left(<17^{\circ} \mathrm{C}\right),\left[\mathrm{Ca}^{2+}\right]_{\mathrm{i}} \text {, alkalosis, } \\
\text { stretch, GPCR, PIP }, \text { PKA. }\end{array}$ & spiratory sensory neuron & $\begin{array}{l}\text { environmental } \\
\text { irritants } \\
\text { (acrolein), } \\
\text { allicin, allyl } \\
\text { isothocyanate, } \\
\text { citral, NSAIDs, } \\
\text { eugenol, } \\
\text { cinnamaldehyd, } \\
\text { 2-APB, } \\
\text { GsMTX-4 }\end{array}$ & HC-030031 \\
\hline TRPV1 & $\begin{array}{l}\text { heat }\left(>43^{\circ} \mathrm{C}\right) 、 \text { acidity } \\
(\mathrm{pH}<5.9) 、 12-\mathrm{HETE}, 12-\mathrm{LOX} \\
\text { metabolites, anandamide, } \\
\text { chemokines } \text {. GPCR (e.g. } \\
\text { bradykinin, ATP, PAR2)、NGF, } \\
\text { GDNF, PKA, PKC, PI3K, } \\
\mathrm{Ca}^{2+} / \mathrm{CaM}, \mathrm{CaMK} \text { II, src, } \\
\text { calcineurin, Ras/MAPK, SCF }\end{array}$ & autonomic imbalance & $\begin{array}{l}\text { enviromental } \\
\text { irritants, } \\
\text { capsaicin, 2- } \\
\text { APB - camphor, } \\
\text { allicin, citral, } \\
\text { resiniferatoxin, } \\
\text { gingerol, } \\
\text { eugenol, EtOH }\end{array}$ & $\begin{array}{l}\text { capasazeine, } \\
\text { ABT-102, AMG-517, } \\
\text { GRC-6211, MK- } \\
\text { 2295, SB-366791, } \\
\text { SB-705498, }\end{array}$ \\
\hline
\end{tabular}

Table 1. Arrhythmogenic TRP channels 
Abbreviations; CaM, calmodulin: GPCR, G-protein-coupled receptor (Gq-coupled): const-act, constitutively active: BDNF, brain-derived neurotrophic factor: DAG, diacylglycerol: PKC, protein kinase C: PKG, protein kinase G: LPC, lysophosphatidylcholine: S1P, sphingosin 1phosphate: EGF, epidermal growth factor: PGE2, prostaglandin E2: 20-HETE, 20hydroxytetraenoic acid: PIP3, phosphatidylinositol 3,4,5-trisphospate: PIP2, phosphatidylinositol 4,5-trisphospate: CaMKII, calmodulin-dependent kinase II: ADPR, ADP ribose: cADPR, cyclic ADP ribose: NAADP, nicotinic acid adenine dinucleotide phosphate: PKA, protein kinase A: 12HETE, 12-hydroxy-5,8,10,14-eicosatetraenoic acid: LOX, lipooxygenase: PAR2, Proteinaseactivated receptor 2: NGF, nerve growth factor: GDNF, glial cell-line derived neurotrophic factor: MAPK, mitogen-activated protein kinase: SCF, stem cell factor: SKF, SK\&F96365: BTP-2, 4methyl-4 -[3,5-bis(trifluoromethyl)-1H-pyrazol-1-yl]-1,2,3-thiadiazole-5-carboxanilide: Pyr-2, Ethyl-1-(4-(2,3,3-trichloroacrylamide)phenyl)-5-(trifluoroluoromethyl)-1H-pyrazole-4carboxylate: 2-APB, 2-aminoethoxydiphenyly boroate, 9-PA, 9-phenanthrol.

\subsection{Stretch-induced arrhythmia in pathological settings}

As described above, acute stretch of cardiac muscle can induce arrhythmic responses in both atrium and ventricle, which are inhibited by widely used MSCC blockers Gd ${ }^{3+}$ and GsMTx4. This has led to the speculation that activation of nonselective cationic MSCCs causes premature depolarizations. There are at least three candidates for these MSCCs in TRPs expressed in the heart, i.e. TRPC1, TRPC6 and TRPM4.

In both heterologous and native overexpression systems, TRPC1 and TRPC6 have been found to activate in response to mechanical stimuli (Maroto et al.,2005; Spassova et al., 2006). Albeit controversial (e.g. Inoue et al., 2009a), the so-called MSCC-selective peptide blocker GsMTx-4 has been found to inhibit the mechanical activation of both TRPC1- and TRPC6mediated MSCC activities (Maroto et al.,2005; Spassova et al., 2006). TRPC1 and TRPC6 are ubiquitously expressed in whole myocardial tissues (Huang et al, 2009; Ward et al., 2008), and GsMTx-4 suppresses stretch-induced force development and concomitant $\left[\mathrm{Ca}^{2+}\right]_{\mathrm{i}}$ increase in mouse left ventricular trabecular muscle (Ward et al., 2008) and pressureinduced atrial fibrillation (Franz and Bode, 2003). Moreover, the expression of TRPC1 and TRPC6 is greatly increased in hypertrophied heart under prolonged pressure overload (Kuwahara, et al; 2006; Ohba, et al., 2007), where the susceptibility to mechanically-induced arrhythmia is also enhanced (Kamkin et al., 2000a). All these observations favor the view that TRPC1 and TRPC6 contribute to stretch-induced arrhythmias as MSCCs in some pathological settings. However, there is controversy over the mechanosensitivity of these two TRPC channels. In knock-out mice deficient in TRPC1 or TRPC6 expression, pressureinduced vasoconstriction (myogenic response), which is believed to reflect the depolarizing effects of MSCC activation, was found intact (Dietrich et al., 2005; Gottlieb et al., 2007). Although this fact could not totally negate the roles of these TRP channels in the heart, it is essential to test whether mechanical activation of myocardial MSCCs and mechanical arrhythmogenicity are indeed impaired in these knock-out mice or vice versa in TRPC1- or TRPC6-overexpressing mice. Alternatively, it may also deserve to test the possible involvement of a recently identified GsMTx-4-sensitive MSCC, Piezo1/Piezo2, in stretchinduced arrhythmia in the heart (Bae et al., 2011).

In cerebral arterial myocytes, TRPM4 has been proposed as a MSCC responsible for myogenic response (Earley et al., 2004). However, again, the results from TRPM4-deficient mice do not support this role (for more detail, see below) (Mathar et al., 2010). Nevertheless, 
it is noteworthy that TRPM4 can be secondarily activated by mechanical stretch through stretch-induced $\mathrm{Ca}^{2+}$ release from ryanodine-sensitive stores in arterial myocytes (Morita et al., 2007), since similar axial stretch-induced $\mathrm{Ca}^{2+}$ release from the SR has been demonstrated in cardiomyocytes (Iribe, et al., 2009). Considering that heart wall is periodically distended by diastolic filling pressure, this mechanosensitive mechanism may have considerable pathophysiological significance for the genesis of DAD in remodeled heart in which the expression of TRPM4 and $\mathrm{Ca}^{2+}$ loading into SR are prominently enhanced (see below).

It has been shown that repeated cyclic stretch induces hypertrophic responses of cardiac myocytes, which are significantly attenuated by antagonists for a PLC-linked G-protein coupled receptor (GPCR), angiotensin type $1\left(\mathrm{AT}_{1}\right)$ receptor (Komuro and Yazaki, 1993). This is explained by direct mechanical activation of unoccupied $\mathrm{AT}_{1}$ receptor as demonstrated by the substituted cysteine accessibility mapping technique (Yasuda et al., 2008). Similar mechanical activation also appears to occur for many other PLC-linked GPCRs including endothelin $\mathrm{ET}_{\mathrm{A}}$, vasopressin $\mathrm{V}_{1 \mathrm{~A}}$ and muscarinic $\mathrm{M}_{5}$ receptors (Mederos y Schnitzler et al., 2008). TRPC6 and its homologue TRPC3 are activated by stimulation of PLC-coupled GPCRs via generation of diacylglycerol (DAG) (Hofmann, et al., 1999) and $\mathrm{Ca}^{2+}$ influx through activated TRPC3 and TRPC6 channels has been shown to be essential for hypertrophic responses of caridomyocyte via calcineurin/NFAT pathway (Kuwahra et al., 2006; Bush et al., 2006; Onohara et al., 2006). In failing hearts where pressure overload is sustained, the release of catecholamines from sympathetic nerves and adrenal gland is increased (see above), and the production of angiotensin II (AngII) and expression of $\mathrm{AT}_{1}$ receptor and angiotensin converting enzyme are greatly enhanced (Goette, A et al., 2000; Ihara M et al, 2000; Kaprielian RR et al., 1997). Moreover, the mechanosensitivity of TRPC6 channel is remarkably enhanced by the simultaneous stimulation of PLC-linked GPCRs via concerted actions of two lipid messengers DAG and 20-HETE (Inoue et al., 2009a). Thus, taken together, it is highly conceivable that sustained mechanical loads promote the hypertrophic remodeling of cardiomyocytes through synergistic interplay between excessive activation of GPCR-PLC pathways and enhanced receptor/mechanical activation of TRPC6 (and TRPC3) channels. This would in turn exacerbate $\mathrm{Ca}^{2+}$ overload into the myocyte SR to increase the propensity for pro-arrhythmic depolarizations. Consistent with this scenario, cardiac-specific TRPC6 transgenic mice have been found to exhibit much increased susceptibility to mechanical stress with increased incidence of sudden death accompanied by severe macroscopic and histological signs of cardiomyopathy (Kuwahara et al., 2006). The same study also found that expression of TRPC6 was several-fold upregulated in human failing heart. Obviously, detailed electrophysiological analyses are required to corroborate whether the above changes could indeed induce the arrhythmogenicity.

\section{2 $\mathrm{Ca}^{2+}$-dependent arrhythmia}

Abnormal $\mathrm{Ca}^{2+}$ handling or cycling in cardiac tissues is the main cause for arrhythmia (Ter Keurs \& Boyden, 2007). As briefly introduced above, diastolic $\mathrm{Ca}^{2+}$ release (or leak) from the $\mathrm{SR}$ is a key event to initiate arrhythmogenic premature depolarizations DAD. Presently, the mechanism whereby DAD is generated by the $\mathrm{Ca}^{2+}$ release can be accounted for by the activation of three ionic conductances which can generate $\mathrm{I}_{\mathrm{ti}}$ near the resting membrane potential; an electrogenic forward-mode NCX1 current which allows the influx of three $\mathrm{Na}^{+}$ ions in exchange of one $\mathrm{Ca}^{2+}$ efflux after the repolarization has completed; and $\mathrm{Ca}^{2+}$ activated $\mathrm{Cl}^{-}$and nonselective cation channel (CAN) currents. Although the most accepted hypothesis suggests that $\mathrm{I}_{\mathrm{ti}}$ is carried exclusively by enhanced forward-mode NCX1 inward 
current in failing ventricle (Pogwizd, et al. 2001; Pogwizd, 2003; Wu and Anderson, 1999), there is also experimental evidence suggesting the involvement of $\mathrm{Ca}^{2+}$-activated $\mathrm{Cl}^{-}$current (Han et al., 1996; Laflamme et al., 1996) and CAN (Hill et al., 1988; Kass et a., 1978; Wu \& Anderson, 2000) in the genesis of $\mathrm{I}_{\mathrm{ti}}$.

CAN constitutes a large heterogenous family of cation channels with varying unitary conductances, $\mathrm{Ca}^{2+}$-sensitivities, voltage dependence and regulations, and distributes broadly in neurons, smooth muscle, heart, exocrine and endocrine glands, and other epithelial tissues (Siemen, 1993). The most frequently recorded CAN from cardiac tissues, first identified in a cultured rat neonatal ventricular myocyte (Colquhoun, 1981), is a 20$40 \mathrm{pS}$ channel with almost equal selectivity over monovalent cations and poor permeability to divalent cations (Guinamard et al, 2006). Albeit rather great variations, these cardiac CANs are activated by the micro- to mili-molar range of $\mathrm{Ca}^{2+}$ and voltage-dependent. The molecular identification that best fits this type of CAN is now thought to be TRPM4 protein (Launay et al., 2002). Expressed TRPM4 channel shows a $\sim 25 \mathrm{pS}$ conductance (in nearphysiological ionic milieu), is monovalent cation-selective, and, in cell-free conditions, undergoes $\mathrm{Ca}^{2+}$-dependent activation and depolarization-dependent enhancement of open probability only in their unphysiologically high ranges. However, it has been found that the $\mathrm{Ca}^{2+}$ - and voltage-sensitivities of TRPM4 rapidly shift to their much higher ranges immediately after the excision of patch membrane ('desensitization' or 'rundown'), and this is substantially prevented by pretreatment with MgATP, protein kinase C activators, maneuvers replenishing phosphatidylinositol 4,5-bisphosphate and increased temperature (Nilius, 2006). These findings suggest that, in vivo, TRPM4 may be more effectively regulated by physiological ranges of $\left[\mathrm{Ca}^{2+}\right]_{i}$ and membrane potential. Expressed TRPM4 channel also undergoes negative regulation of free adenosine nucleotide phosphates (efficacy; ADP > ATP = AMP), and is subject to spermine block, so that severe ischemic conditions might affect this channel activity (Nilius et al., 2004).

In human, cardiac expression of TRPM4 is ubiquitous in the order of abundance; Purkinje fibers, septum, atrium, left and right ventricles (Kruse et al., 2009). Guinamard et al (2002) found that expression of TRPM4-like CAN, which was virtually absent at the time of cell isolation, was progressively enhanced in rat dedifferentiating ventricular myocytes with the time of culture. Studies from the same group also found that purinergic receptor activation by ATPYS, PKC activators and DAG, all of which act as interventions to facilitate cardiac remodeling, enhanced the occurrence of TRPM4-like channel in cultured ventricular myocytes. This led to the postulation that remodeling of ventricular myocytes in response to excessive hypertrophic signals may enhance the activity of TRPM4 thereby increasing arrhythmogenic propensity mostly likely by increasing DAD. Consistent with this, in the hypertrophic heart of spontaneously hypertensive rat, the elongation of Q-T interval in electrocardiogram has been reported together with increased expression of TRPM4 protein and density of CAN (Guinamard et al., 2006). Recent reports indicate that TRPM4 is more abundantly expressed in atrium and sinoatrial node (Demion et al, 2007; Guinamard, 2004; Kruse et al., 2009), where DAD-based tachyarrhythmias have been well established (Dobrev, 2010; Guinamard 2006; Nattel 2007; Raves, 2010). However, TRPM4-deficient mice showed no obvious abnormalities in heart rate, cardiac output, ejection fraction and cardiac contractility at basal conditions questioning a vital role of TRPM4 in physiological regulation of cardiac functions (Mathar et al., 2009). Rather unexpectedly, the genetic deletion of TRPM4 caused postnatal development of high blood pressure due to increased sympathetic catecholamine secretion. These seemingly paradoxical observations might point to the pathological contribution of TRPM4 to 
arrhythmogenicity in diseased remodeling heart rather than to normal rhythm formation, in which the expression and activity of TRPM4 are enhanced.

A recent genetic analysis of human families with lethal conduction failure has found a gainof-function mutation (c.19G $\rightarrow \mathrm{A}$ in exon 1 or p.E7K) in the N-terminal domain of TRPM4 channel (PFHBI; progressive familial heart block type I) (Kruse et al., 2009). More recently, other TRPM4 mutations with very similar biological impacts (p.R164W, p.A432T, p.G844D) have also been assigned to autosomal dominant isolated cardiac conduction block (ICCD) of Lebanese and French families (Liu et al., 2010). Biochemical and immunocytochemical data suggested that these mutations increase the cell surface expression of TRPM4 protein due to desregulated SUMOylation/deSUMOylation process which results in impaired endocytotic protein degradation. The accompanying electrophysiological changes for these mutations are consistent with the biochemical/immunicytochemical data; the density of whole-cell CAN current was increased with little noticeable changes in macroscopic $\mathrm{Ca}^{2+}$ sensitivity and voltage dependence or in unitary conductance and open probability at single channel level. These results suggest that the number of functional channels were increased without altered biophysical properties. The precise pathogenic mechanism for these mutations to cause conduction block remains unclear. However, RT-PCR analysis indicated the highest expression of TRPM4 in Purkinje fiber, and detailed immunohistochemical examination showed strongly TRPM4-positive subendocardial bundles of Purkinje fibers branching and penetrating toward subepithelial layer (Kruse et al., 2009; Liu et al., 2010). These morphological findings, combined with a broadened QRS complex in ECG in both PFHBI and ICCD patients, led the authors to speculate that elevated TRPM4 expression may increase the membrane leak conductance thereby disabling action potential propagation along the Purkinje fibers. There are several previous studies showing that $\mathrm{Ca}^{2+}$ overload causes membrane oscillations in Purkinje fibers due to increased spontaneous $\mathrm{Ca}^{2+}$ release when $\mathrm{Na}^{+}$extrusion via $\mathrm{Na}^{+} / \mathrm{K}^{+}$-ATPase was pharmacologically inhibited (Kass et al., 1978; Kass \& Tsien, 1982; Lederer \& Tsien, 1976). Considering that TRPM4 may also act as a $\mathrm{Na}^{+}$ entry pathway in response to GPCR stimulation (Launay, et al., 2002), the resultant increase in $\left[\mathrm{Na}^{+}\right]_{\mathrm{i}}$ might then elevate $\left[\mathrm{Ca}^{2+}\right]_{\mathrm{i}}$ via the reversed mode operation of NCX1 in Purkinje fiber cells (Bers, 2006; Pogwizd, 2003). This would not only facilitate $\mathrm{Ca}^{2+}$ overload and DAD generation due to increased TRPM4 channel activation, but could also induce cell death leading to cardiac injury/remodeling if the elevation of $\left[\mathrm{Ca}^{2+}\right]$ would persist. Fibrotic replacement observed in the His-Purkinje fiber system of a PFHBI patient (Kruse et al., 2009) may support the latter possibility. Thus, the depolarizing and $\mathrm{Na}^{+}$-permeating properties of TRPM4 channel could bring about both acute (induction of DAD) and chronic (conduction block due to remodeling) pro-arrhythmic effects.

\subsection{Arrhythmia associated with ischemia and oxidative stress}

In the acute phases of myocardial infarction, many arrhythmogenic substances are released (see above). ATP and UTP are amongst these, being released from cardiomycytes during ischemia and may promote the occurrence of ventricular tachyarrhythmias (Dutta et al., 2004; Kuzmin et al., 1998). In vitro, ATP can induce DAD-based arrhythmic depolarizations in single cadiomyocytes when combined with $\mathrm{Ca}^{2+}$ increasing agents such as catecholamines (Song \& Belardinelli, 1994). In voltage-clamped adult ventricular myocytes, ATP/UTP can activate a sustained inward current via P2Y2 receptor and enhance the opening of 14 and 23pS single channel activities in a PLC-dependent manner. TRPC3 and TRPC7 proteins from rat ventricular myocytes immunocoprecipitated, and the macroscopic current induced by 
ATP was suppressed by intracellular application of anti-TRPC3 antibody from the patch pipette (Alvarez et al., 2008). These findings are collectively interpreted as indicating that ATP/UTP may cause arrhythmia by activating TRPC3/TRPC7 heterotetrameric $\mathrm{Ca}^{2+}$ and $\mathrm{Na}^{+}$entry channels whereby to facilitate intracellular $\mathrm{Ca}^{2+}$ overloading and trigger electrical activities. Consistent with this scenario, the same researchers' group has recently shown that flash photolysis of caged ATP can evoke one or even a train of extrasystolic contractions. Further, intraperitoneal injection of creatine, which is capable of buffering a sudden ATP/UTP release and clinically exhibits anti-arrhythmic effects, markedly reduced ventricular tachyarrhythmias and early death events in a rat coronary-ligature myocardial infarction model. These ameliorating effects of creatine were defective in an inactive creatine analogue $\beta$-guanidinopropionate (Vassort et al., 2010). Cell surface expression of TRPC3 was found tightly controlled by vesicular trafficking, cytoskeletal actin dynamics and interaction with caveolar or subsarcolemmal proteins and molecules (Groschner K, et al., 2005). And PLC stimulation by AngII in cardiomycytes was reported to facilitate the recruitment of TRPC3 complexed with NCX1 to cell membrane, resulting in the reverse mode $\mathrm{Ca}^{2+}$ entry through NCX1 (Eder et al., 2007). Thus, although the precise connection between TRPC3 (and possibly TRPC7) channel activation by ATP and arrhythmogenicty is unclear, the above mechanism may have particular pathophysiological significance in $\mathrm{Ca}^{2+}$-dependent arrhythmogenesis during postinfaction remodeling period or sudden ischemic insult of hypertrophied heart, where enhanced expression of TRPC3 and sympathetic nerve activity play pivotal roles. Seemingly in line with these results, a recent independent study has reported that cardiomyocytes from TRPC3-overexressing mice show an increased susceptibility to apoptotic death due to $\mathrm{Ca}^{2+}$ overload when subjected to hypoxia/reoxgenation (Shan et al., 2007).

Oxidative stress causes tissue damage in a variety of pathological states including aging, cancer, neurogenerative disorders, autoimmune diseases, atherosclerosis and ischemia/reperfusion injury of myocardium (Chandra et al., 2000; Langley et al., 2004; Misra et al., 2009). Many reactive oxygen spices (ROS; $\mathrm{O}_{2}^{-} \cdot \cdot \cdot \mathrm{OH}, \mathrm{H}_{2} \mathrm{O}_{2}, \mathrm{NO}$, $\cdot \mathrm{ONOO}-$ ) are generated as the result of ischemia and reoxygenation and may confer the susceptibility to arrhythmia in direct and indirect ways (via modifying autonomic nerve activity (Danson et al., 2006; Misra et al., 2009). Several TRP members including TRPM2, TRPM7, TRPC5 and a TRPC3/TRPC4 heterooligomer are known to be activated by oxidative stresses (Miller \& Zhang, 2011; Naylor et al., 2011; Poteser et al., 2006). TRPM2 is the first reported ROSsensitive $\mathrm{Ca}^{2+}$-permeable nonselective cation channel activated by $\mathrm{H}_{2} \mathrm{O}_{2}$, ADP-ribose, TNFa, and $\beta$-amyloid peptide, and is implicated in both physiological functions and pathophysiology including oxidant $\left(\mathrm{H}_{2} \mathrm{O}_{2}\right)$-induced cell damage/death in pancreatic $\beta$-cells and neurons. TRPM2 is positively regulated by intracellular $\mathrm{Ca}^{2+}$, and its cell damaging action appears to be mediated at least in part by sustained $\left[\mathrm{Ca}^{2+}\right]_{\mathrm{i}}$ elevation (Takahashi et al., 2011). In myocardial infarction, reperfusion injury and congestive heart failure, elevated plasma levels of TNFa have been reported (Sack et al., 2000). TNFa can activate both cytotoxic and cytoprotective signaling pathways in many cell types including mitochondrial ROS production through the recruitment of caspase- 8 into the death-inducing signaling complex (Kroemer et al., 2007; Zhu et al., 2006). Further, altered redox state changes the activity of cardiac ion channels and transporters regulating $\mathrm{Ca}^{2+}$ dynamics in the cardiomyocyte, i.e. L-type $\mathrm{Ca}_{\mathrm{v}}, \mathrm{RyR2}$, NCX1 and SERCA2a (Zima \& Blatter, 2006). In keeping with these observations, activation of TRPM2 by oxidative stress $\left(\mathrm{H}_{2} \mathrm{O}_{2}\right)$ has been found to cause apoptotic/necrotic changes in single cardiomyocytes with ultrastructural 
changes characteristic of cardiac ischemia/reperfusion injury (Yang et al, 2006). Although whether these changes are pro-arrhythmic remains to be explored, it is possible that sustained $\left[\mathrm{Ca}^{2+}\right]_{i}$ elevation through activated TRPM2 channel would disturb basal $\mathrm{Ca}^{2+}$ homeostasis underlying rhythmic excitations in cardiomyocytes thereby inducing $\mathrm{Ca}^{2+}$ dependent arrhythmogenicity. The arrhythmogenic effect of TRPM2 may not necessarily be restricted to direct cell-damaging actions via sustained $\left[\mathrm{Ca}^{2+}\right]_{i}$ elevation. It could occur indirectly through the production of inflammatory cytokines from ambient immune cells, as was demonstrated in an animal model of inflammatory bowel syndrome (Yamamoto et al., 2008).

In addition, expression of TRPC4 and TRPC5 was found to increase 2-3-fold in cultured rat cardiomyocytes subjected to downregulation of SERCA by siRNA technology which mimics the remodeling process of diseased heart (Seth et al., 2004). TRPC5 is known to be activated by many noxious stimuli such as $\mathrm{H}_{2} \mathrm{O}_{2}$ and LPC (Flemming et al., 2006; Naylor et al., 2011), and thus could act as a pro-arrhythmic mediator in ischemic remodeling heart. This possibility will be an intriguing subject of future investigation, together with other TRP isoforms implicated in the pathogenesis of cardiomyopathy (TRPV2, TRPC7; Iwata et al., 2003; Satoh et al., 2007).

\subsection{Arrhythmia related to fibrosis}

Cardiac fibroblasts occupy about $70 \%$ of whole cardiac cell populations, and, once placed in pathological states such as myocardial injury, oxidative stress and excessive mechanical stretch, start to proliferate and differentiate into the active phenotype 'myofibroblast'. Activated myofibroblasts secrete extracellular matrix proteins (e.g. collagen), matrix metaloproteinases, cytokines and growth factors thereby promoting the pathological restructuring of diseased heart with fibrotic replacement of damaged myocardial tissue (Souders, et al., 2009). Cardiac fibroblasts have a shallow resting membrane potential (-30 - $10 \mathrm{mV}$ ) and are non-excitable themselves, but show mechanically-induced depolarizations well synchronized with spontaneous contractions of myocardium (Kamkin et al, 2000b; Kamkin et al, 2003). These electrophysiological properties allow them, by coupling electrically to myocytes as a leaky capacitor, to modify the electrical properties of myocyte action potential and its propagation (Yue et al., 2011). In contrast, fibrotic tissues generated by myofibroblasts act as a physical barrier insulating the spread of electrical currents between the bundles of cardiomyocytes. Thus, disturbances in the myocyte-fibroblast coupling and alterations in myocardial architecture due to spatially inhomogenous fibrosis can lead to cardiac arrhythmias associated with reentry or conduction block.

It has been known that fibrotic remodeling is a fundamental process underlying the perpetuation of AF. Atrial fibrosis is dependent on $\mathrm{Ca}^{2+}$, but what source of $\mathrm{Ca}^{2+}$ is involved therein had been elusive. A recent study of Du et al. (2010) demonstrated that upregulation of TRPM7, a constitutively active $\mathrm{Ca}^{2+} / \mathrm{Mg}^{2+}$ entry channel (Wu et al, 2010), and resultant $\mathrm{Ca}^{2+}$ influx was crucial for the progression of atrial fibrosis in AF patients. This was supported by the following evidence; (1) human atrial fibroblasts express TRPM7 protein abundantly, and show basal $\mathrm{Ca}^{2+}$ influx and spontaneously active $\mathrm{Ca}^{2+}$-permeable inward currents with the fingerprint features of heterologously expressed TRPM7 channels [potentiation by low $\mathrm{pH}$ and inhibition/potentiation by low/high concentrations of 2aminoethoxydiphenyly boroate (2-APB) respectively: Li et al., 2006, 2007]; (2) TRPM7-like current and accompanying $\mathrm{Ca}^{2+}$ influx were strikingly increased in parallel with the upregulation of TRPM7 expression in differentiated fibroblasts from AF patients; (3) all 
these changes were largely eliminated by knockdown of TRPM7 expression with small hairpin RNA; and (4) in vitro promotion of myofibroblastic differentiation by TGF- $\beta 1$, a major stimulator of atrial fibrosis, was correlated with the upregulation of TRPM7. Although in this study a direct linkage between $\mathrm{Ca}^{2+}$ influx through TRPM7 channel, the fibrogenesis and arrhythmogenesis in AF have not been explored, the above results may provide a new therapeutic target against the progression of $\mathrm{AF}$, by disclosing an essential role of TRPM7-asscociated $\mathrm{Ca}^{2+}$ influx in fibroblast proliferation and differentiation.

In rat neonatal cardiac fibroblasts, endothelin-1 (ET-1) or AngII can induce myofibroblastic differentiation and collagen synthesis via the $\mathrm{Ga}_{12 / 13}$ signaling. $\mathrm{ET}-1$ (via $\mathrm{ET}_{\mathrm{A}}$ receptor) and AngII can also selectively enhance the expression of TRPC6, thereby increasing basal $\mathrm{Ca}^{2+}$ influx in the fibroblasts. Importantly, increased TRPC6 expression is causally correlated with anti-fibrotic effects via calcineurin/NFAT pathway (Nishida et al., 2007). The upregulation of TRPC6 likely occurs through the $\mathrm{G}_{12 / 13^{-}}$(Rac/NOX)-ROS-JNK signaling, which is reminiscent of TRPC6-mediated abnormal proliferation of pulmonary artery smooth muscle cells induced by platelet-derived growth factor, a pathogenic model of pulmonary artery hypertension (Yu et al., 2003). The concentrations of ET-1 or AngII required to upregulate TRPC6 are significantly higher than those for the differentiation of fibroblasts (Nishida et al., 2007). Thus, in an intriguing contrast to the pro-fibrotic role of TRPM7, the anti-fibrotic effects of enhanced TRPC6 channel activity may serve as a negative feedback mechanism to limit excessive fibrogenesis via ET-1/AngII signaling during cardiac remodeling. It remains to be determined whether this mechanism works beneficially in human AF patients or other fibrosis-associated arrhythmias.

\subsection{Arrhythmia related to autonomic imbalance}

The cardiac rhythm is under tight control of the autonomic nervous system. For instance, baroreceptors monitor blood pressure fluctuations and transmit the information to the brainstem vasomotor center via parasympathetic afferents, which then modulates the cardiac pumping force and rate via sympathetic efferents. The renin-angiotensinaldosterone system is another well-established system centrally controlled via sympathetic nerves (via $\beta_{1}$-adrenoceptor). It fulfills a long-term control of body fluid and electrolyte balance, thereby effectively regulating the cardiac output (Guyenet, 2006). Any disturbances in these centrally-mediated autonomic regulations could therefore become the substrates for cardiac arrhythmias (Danson, et al., 2006; Janse 2004; Nattel, et al., 2007). Accumulating evidence however suggests that nociceptive reflexes via respiratory sensory neurons (e.g. Cfibers in nose and lung) have also some pathophysiological impact on cardiac functions through centrally-mediated autonomic mechanisms, as exemplified by air pollutantinduced changes in 'repolarization' parameters of ECG (Henneberger et al., 2005). The sensory nerve endings in respiratory airways contain two TRP members sensing noxious stimuli, i.e. TRPV1 and TRPA1 which likely participate in airway chemosensation and inflammation (Bessac \& Jordt, 2008). It has thus been postulated that these TRP isoforms may be involved in nociceptive signaling in the respiratory system (Vay et al., 2011).

Two recent studies have revealed intriguing associations between respiratory sensory TRP channels and arrhythmogenicity. In one experimental model, activation of respiratory sensory neurons by inhalation of concentrated ambient particles significantly affected the cardiac rhythm with decreased heart rate, and shortened QT interval and P wave duration. Abrogation of these cardiac effects by a selective TRPV1 antagonist capsazepine suggested that TRPV1-mediated autonomic reflexes play a central role therein (Ghelfi et al., 2008). In 
another study employing a gaseous pollutant (Hazari et al., 2011), one-day exposure of rats to diesel exhaust gas resulted in increased heart rate with pro-arrhythmic ECG changes of prolonged action potential and shorted repolarization. Notably, these rats showed much heightened sensitivity to aconitine challenge that can induce moderate to lethal ventricular tachyarrhythmias dose-dependently. This pro-arrhythmic change was prevented by pretreatment with a TRPA1 antagonist HC-030031 or by sympathetic blockade with guanethidine, suggesting the involvement of increased sympathetic drive. In addition, partial involvement of TRPV1 in moderate aconitine-induced tachyarrhythmias was also suggested by pharmacological inhibition with a selective TRPV1 antagonist SB-366791. Although detailed mechanisms underlying remain unclear, these results clearly point to the pro-arrhythmic risk of environmentally-induced autonomic imbalance in which sensory chemosensing channels TRPA1 and TRPV1 may play a pivotal role.

\section{Conclusions and therapeutic implications}

The evidence presented above has disclosed that the unique activation profile (e.g. stretchand $\mathrm{Ca}^{2+}$-sensitivities, neurohormonal activation, sensitivity to noxious stimuli) and permeability to $\mathrm{Ca}^{2+}$ and $\mathrm{Na}^{+}$(TRPM4/TRPM5 are however virtually $\mathrm{Ca}^{2+}$-impermeable) render several TRP channels contribute to the acquired arrhythmogenesis during cardiac remodeling and other pathological processes. The examples so far available implicates, at least, TRPC1 and TRPC6 (and possibly their homologues) in stretch-induced arrhythmias in both acute and chronic manners, TRPM4 in $\mathrm{Ca}^{2+}$-dependent arrhythmia and familial conduction block, TRPC3 and TRPM2 in ischemia-induced arrhythmia, TRPA1 and TRPV1 in autonomic imbalance-induced arrhythmia, and TRPM7 and TRPC6 in fibrosis-related arrhythmogenicity, especially in $\mathrm{AF}$, as pro-fibrotic and anti-fibrotic factors respectively. Although the mechanism of the actions of each TRP isoform appears variable in different pathophysiological settings, these new lines of evidence have certainly put forward our essential understanding about the pathogenesis of commonly observed arrhythmias associated with cardiac diseases accompanying structural and electrical remodeling. Simultaneously it may open an avenue toward exploiting an entirely new generation of antiarrhythmic drugs for increased mechanosensitivity, abnormal $\mathrm{Ca}^{2+}$ handling, oxidative stress, or nociception.

When considering the actual strategy for developing such drugs, however, there are at least two not easily tractable problems. The serious lack of structure-based chemical knowledge about the selectivity and efficacy for most TRP members is the first obvious one, although substantial progress is going on for analgesic therapy based on TRPV1 pharmacology (Szallasi et al., 2007). Virtually all drugs so far shown to be effective for cardiovascular TRP isoforms appear to be non-specific or have only narrow ranges of concentrations for their relatively selective actions, as exemplified by a pyrazole compound Pyr-3 for TRPC3 which reportedly inhibits experimentally-induced cardiac hypertrophy (Kiyonaka et al., 2009). The second type of difficulty for exploiting TRP-selective drugs is that connecting one TRP isoform to one end-function is almost always irrelevant oversimplification. This is because signaling pathways linked to TRPs appear to form a complex interwoven network with high degrees of divergence and convergence and with numerous feed-back and -forward regulations. In addition to this, activation of TRP channels depends intimately on local lipid dynamics in the cell membrane, which dramatically changes by lipid composition, voltage, temperature, membrane stretch, and enzyme-assisted catalysis (Hardie, 2007; Inoue et al., 
2009b). In the current absence of good knowledge about lipid physiology/pathophysiology for membrane proteins, these disadvantages would make it difficult to pharmacologically manipulate the gating of TRP channels. In this context, recent observations that activation of the cGMP-PKG signaling by nitric oxide, atrial natriuretic peptides and their structural and functional mimetics attenuate hypertrophic cardiac remodeling partly via inhibition of TRP channels (Inoue et al., 2010; Tsai \& Kass, 2009) may provide a promising alternative maneuver to ameliorate the acquired arrhythmogenicity. Activation of this pathway is also known to improve myocardial damage after myocardial infarction (Burley et al., 2007; Garcia-Dorado et al., 2009). Obviously, there is much to be learned about the pathogenic roles and therapeutic potential of cardiovascular TRP channels for cardiac arrhythmias.

\section{Acknowledgment}

Part of this work is supported by Grants-in-aid for Scientific Research on Innovative Areas (No.22136008) and Scientific Research (C) (No. 21590246), and a grant from Seizon Kagaku Institute to R.I.

\section{References}

Ai, X., Curran, J. W., Shannon, T. R., Bers, D. M., \& Pogwizd, S. M. (2005). Ca ${ }^{2+} /$ calmodulindependent protein kinase modulates cardiac ryanodine receptor phosphorylation and sarcoplasmic reticulum $\mathrm{Ca}^{2+}$ leak in heart failure. Circ Res, 97(12), pp. 13141322.

Alvarez, J., Coulombe, A., Cazorla, O., Ugur, M., Rauzier, J. M., Magyar, J., et al. (2008). ATP/UTP activate cation-permeable channels with TRPC3/7 properties in rat cardiomyocytes. Am J Physiol Heart Circ Physiol, 295(1), pp. H21-28.

Bae, C., Sachs, F.,\& Gottlieb, P.A.(2011). The Mechanosensitive ion channel Piezo1 is inhibited by the peptide GsMTx4. Biochemistry,50, pp. 6295-6300.

Benson, D. W., Silberbach, G. M., Kavanaugh-McHugh, A., Cottrill, C., Zhang, Y., Riggs, S., et al. (1999). Mutations in the cardiac transcription factor NKX2.5 affect diverse cardiac developmental pathways. J Clin Invest, 104(11), pp. 1567-1573.

Bers, D. M. (2006). Altered cardiac myocyte Ca regulation in heart failure. Physiology (Bethesda), 21, pp. 380-387.

Bessac, B. F., \& Jordt, S. E. (2008). Breathtaking TRP channels: TRPA1 and TRPV1 in airway chemosensation and reflex control. Physiology (Bethesda), 23, pp. 360-370.

Bonne, G., Di Barletta, M. R., Varnous, S., Becane, H. M., Hammouda, E. H., Merlini, L., et al. (1999). Mutations in the gene encoding lamin A/C cause autosomal dominant Emery-Dreifuss muscular dystrophy. Nat Genet, 21(3), pp. 285-288.

Burley, D. S., Ferdinandy, P., \& Baxter, G. F. (2007). Cyclic GMP and protein kinase-G in myocardial ischaemia-reperfusion: opportunities and obstacles for survival signaling. Br J Pharmacol, 152(6), pp. 855-869.

Bush, E.W., Ho, D.B., Papst, P.J. et al. (2006). Canonical transient receptor potential channels promote cardiomyocyte hypertrophy through activation of calcineurin signaling. $J$ Biol Chem, 281, pp.33487-96. 
Cerbai, E., Barbieri, M., \& Mugelli, A. (1994). Characterization of the hyperpolarizationactivated current, I(f), in ventricular myocytes isolated from hypertensive rats. $J$ Physiol, 481 ( Pt 3), pp. 585-591.

Chandra, J., Samali, A., \& Orrenius, S. (2000). Triggering and modulation of apoptosis by oxidative stress. Free Radic Biol Med, 29(3-4), pp. 323-333.

Chen, Q., Kirsch, G. E., Zhang, D., Brugada, R., Brugada, J., Brugada, P., et al. (1998). Genetic basis and molecular mechanism for idiopathic ventricular fibrillation. Nature, 392(6673), pp. 293-296.

Clements-Jewery, H., Hearse, D. J., \& Curtis, M. J. (2005). Phase 2 ventricular arrhythmias in acute myocardial infarction: a neglected target for therapeutic antiarrhythmic drug development and for safety pharmacology evaluation. Br J Pharmacol, 145(5), pp. 551-564.

Cohn, J. N., Ferrari, R., \& Sharpe, N. (2000). Cardiac remodeling--concepts and clinical implications: a consensus paper from an international forum on cardiac remodeling. Behalf of an International Forum on Cardiac Remodeling. J Am Coll Cardiol, 35(3), pp. 569-582.

Colquhoun, D., Neher, E., Reuter, H., \& Stevens, C. F. (1981). Inward current channels activated by intracellular Ca in cultured cardiac cells. Nature, 294(5843), pp. 752754.

Danson, E. J., \& Paterson, D. J. (2006). Reactive oxygen species and autonomic regulation of cardiac excitability. J Cardiovasc Electrophysiol, 17 Suppl 1, pp. S104-S112.

de Jong, J. S., \& Dekker, L. R. (2010). Platelets and cardiac arrhythmia. Front Physiol, 1, article 166, pp. 1-8.

Dean, J. W., \& Lab, M. J. (1989). Arrhythmia in heart failure: role of mechanically induced changes in electrophysiology. Lancet, 1(8650), pp. 1309-1312.

Demion, M., Bois, P., Launay, P., \& Guinamard, R. (2007). TRPM4, a Ca ${ }^{2+}$-activated nonselective cation channel in mouse sino-atrial node cells. Cardiovasc Res, 73(3), pp. 531-538.

Dietrich, A., Kalwa, H., \& Gudermann, T. (2010). TRPC channels in vascular cell function. Thromb Haemost, 103(2), pp. 262-270.

Dietrich, A., Kalwa, H., Storch, U., Mederos y Schnitzler, M., Salanova, B., Pinkenburg, O., et al. (2007). Pressure-induced and store-operated cation influx in vascular smooth muscle cells is independent of TRPC1. Pflugers Arch, 455(3), pp. 465-477.

Dobrev, D. Atrial $\mathrm{Ca}^{2+}$ signaling in atrial fibrillation as an antiarrhythmic drug target. Naunyn Schmiedebergs Arch Pharmacol, 381(3), pp. 195-206.

Du, J., Xie, J., Zhang, Z., Tsujikawa, H., Fusco, D., Silverman, D., et al. (2010). TRPM7mediated Ca2+ signals confer fibrogenesis in human atrial fibrillation. Circ Res, 106(5), pp. 992-1003.

Dupont, E., Matsushita, T., Kaba, R. A., Vozzi, C., Coppen, S. R., Khan, N., et al. (2001). Altered connexin expression in human congestive heart failure. J Mol Cell Cardiol, 33(2), pp. 359-371.

Dutta, A. K., Sabirov, R. Z., Uramoto, H., \& Okada, Y. (2004). Role of ATP-conductive anion channel in ATP release from neonatal rat cardiomyocytes in ischaemic or hypoxic conditions. J Physiol, 559(Pt 3), pp. 799-812. 
Earley, S., Waldron, B. J., \& Brayden, J. E. (2004). Critical role for transient receptor potential channel TRPM4 in myogenic constriction of cerebral arteries. Circ Res, 95(9), pp. 922-929.

Eder, P., Probst, D., Rosker, C., Poteser, M., Wolinski, H., Kohlwein, S. D., et al. (2007). Phospholipase C-dependent control of cardiac calcium homeostasis involves a TRPC3-NCX1 signaling complex. Cardiovasc Res, 73(1), pp. 111-119.

Fedak, P. W., Verma, S., Weisel, R. D., \& Li, R. K. (2005). Cardiac remodeling and failure: from molecules to man (Part I). Cardiovasc Pathol, 14(1), pp. 1-11.

Fernandez-Velasco, M., Goren, N., Benito, G., Blanco-Rivero, J., Bosca, L., \& Delgado, C. (2003). Regional distribution of hyperpolarization-activated current (If) and hyperpolarization-activated cyclic nucleotide-gated channel mRNA expression in ventricular cells from control and hypertrophied rat hearts. J Physiol, 553(Pt 2), pp. 395-405.

Flemming, P. K., Dedman, A. M., Xu, S. Z., Li, J., Zeng, F., Naylor, J., et al. (2006). Sensing of lysophospholipids by TRPC5 calcium channel. J Biol Chem, 281(8), pp. 4977-4982.

Franz, M. R., \& Bode, F. (2003). Mechano-electrical feedback underlying arrhythmias: the atrial fibrillation case. Prog Biophys Mol Biol, 82(1-3), pp. 163-174.

Garcia-Dorado, D., Agullo, L., Sartorio, C. L., \& Ruiz-Meana, M. (2009). Myocardial protection against reperfusion injury: the cGMP pathway. Thromb Haemost, 101(4), pp. 635-642.

Ghelfi, E., Rhoden, C. R., Wellenius, G. A., Lawrence, J., \& Gonzalez-Flecha, B. (2008). Cardiac oxidative stress and electrophysiological changes in rats exposed to concentrated ambient particles are mediated by TRP-dependent pulmonary reflexes. Toxicol Sci, 102(2), pp. 328-336.

Goette, A., Staack, T., Rocken, C., Arndt, M., Geller, J. C., Huth, C., et al. (2000). Increased expression of extracellular signal-regulated kinase and angiotensin-converting enzyme in human atria during atrial fibrillation. J Am Coll Cardiol, 35(6), pp. 16691677.

Gottlieb, P., Folgering, J., Maroto, R., Raso, A., Wood, T. G., Kurosky, A., et al. (2008). Revisiting TRPC1 and TRPC6 mechanosensitivity. Pflugers Arch, 455(6), pp. 10971103.

Groschner, K., \& Rosker, C. (2005). TRPC3: a versatile transducer molecule that serves integration and diversification of cellular signals. Naunyn Schmiedebergs Arch Pharmacol, 371(4), pp. 251-256.

Guinamard, R., Chatelier, A., Demion, M., Potreau, D., Patri, S., Rahmati, M., et al. (2004). Functional characterization of a $\mathrm{Ca}^{2+}$-activated non-selective cation channel in human atrial cardiomyocytes. J Physiol, 558(Pt 1), pp. 75-83.

Guinamard, R., Chatelier, A., Lenfant, J., \& Bois, P. (2004). Activation of the $\mathrm{Ca}^{2+}$-activated nonselective cation channel by diacylglycerol analogues in rat cardiomyocytes. $J$ Cardiovasc Electrophysiol, 15(3), pp. 342-348.

Guinamard, R., Demion, M., Chatelier, A., \& Bois, P. (2006). Calcium-activated nonselective cation channels in mammalian cardiomyocytes. Trends Cardiovasc Med, 16(7), pp. 245-250. 
Guinamard, R., Demion, M., Magaud, C., Potreau, D., \& Bois, P. (2006). Functional expression of the TRPM4 cationic current in ventricular cardiomyocytes from spontaneously hypertensive rats. Hypertension, 48(4), pp. 587-594.

Guinamard, R., Rahmati, M., Lenfant, J., \& Bois, P. (2002). Characterization of a $\mathrm{Ca}^{2+}$ activated nonselective cation channel during dedifferentiation of cultured rat ventricular cardiomyocytes. J Membr Biol, 188(2), pp. 127-135.

Guyenet, P. G. (2006). The sympathetic control of blood pressure. Nat Rev Neurosci, 7(5), pp. 335-346.

Hamill, O. P., \& Martinac, B. (2001). Molecular basis of mechanotransduction in living cells. Physiol Rev, 81(2), pp. 685-740.

Han, X., \& Ferrier, G. R. (1992). Ionic mechanisms of transient inward current in the absence of $\mathrm{Na}^{+}-\mathrm{Ca}^{2+}$ exchange in rabbit cardiac Purkinje fibres. J Physiol, 456, pp. 19-38.

Hansen, D. E., Borganelli, M., Stacy, G. P., Jr., \& Taylor, L. K. (1991). Dose-dependent inhibition of stretch-induced arrhythmias by gadolinium in isolated canine ventricles. Evidence for a unique mode of antiarrhythmic action. Circ Res, 69(3), pp. 820-831.

Hardie, R. C. (2007). TRP channels and lipids: from Drosophila to mammalian physiology. J Physiol, 578(Pt 1), pp. 9-24.

Hazari, M. S., Haykal-Coates, N., Winsett, D. W., Krantz, Q. T., King, C., Costa, D. L., et al. (2011). TRPA1 and sympathetic activation contribute to increased risk of triggered cardiac arrhythmias in hypertensive rats exposed to diesel exhaust. Environ Health Perspect, 119(7), pp. 951-957.

Henneberger, A., Zareba, W., Ibald-Mulli, A., Ruckerl, R., Cyrys, J., Couderc, J. P., et al. (2005). Repolarization changes induced by air pollution in ischemic heart disease patients. Environ Health Perspect, 113(4), pp. 440-446.

Hill, J. A., Jr., Coronado, R., \& Strauss, H. C. (1988). Reconstitution and characterization of a calcium-activated channel from heart. Circ Res, 62(2), pp. 411-415.

Hofmann, T., Obukhov, A. G., Schaefer, M., Harteneck, C., Gudermann, T., \& Schultz, G. (1999). Direct activation of human TRPC6 and TRPC3 channels by diacylglycerol. Nature, 397(6716), pp. 259-263.

Holzer, P. TRP channels in the digestive system. (2011). Curr Pharm Biotechnol, 12(1), pp. 2434.

Huang, H., Wang, W., Liu, P., Jiang, Y., Zhao, Y., Wei, H., et al. (2009). TRPC1 expression and distribution in rat hearts. Eur J Histochem, 53(4), pp. 217-223.

Ihara, M., Urata, H., Shirai, K., Ideishi, M., Hoshino, F., Suzumiya, J., et al. (2000). High cardiac angiotensin-II-forming activity in infarcted and non-infarcted human myocardium. Cardiology, 94(4), pp. 247-253.

Inoue, R., Jensen, L. J., Jian, Z., Shi, J., Hai, L., Lurie, A. I., et al. (2009a). Synergistic activation of vascular TRPC6 channel by receptor and mechanical stimulation via phospholipase $\mathrm{C} /$ diacylglycerol and phospholipase $\mathrm{A}_{2} / \omega$-hydroxylase/20-HETE pathways. Circ Res, 104(12), pp. 1399-1409.

Inoue, R., Jian, Z., \& Kawarabayashi, Y. (2009b). Mechanosensitive TRP channels in cardiovascular pathophysiology. Pharmacol Ther, 123(3), pp. 371-385. 
Inoue, R., Shi, J., Jian, Z., Imai, Y. (2010) Regulation of cardiovascular TRP channel functions along the NO-cGMP-PKG axis. Expert Review of Clinical Pharmacology, 3(3), pp.347360 .

Iribe, G., Ward, C. W., Camelliti, P., Bollensdorff, C., Mason, F., Burton, R. A., et al. (2009). Axial stretch of rat single ventricular cardiomyocytes causes an acute and transient increase in Ca2+ spark rate. Circ Res, 104(6), pp. 787-795.

Iwata, Y., Katanosaka, Y., Arai, Y., Komamura, K., Miyatake, K., \& Shigekawa, M. (2003). A novel mechanism of myocyte degeneration involving the Ca2+-permeable growth factor-regulated channel. J Cell Biol, 161(5), pp. 957-967.

Jalife, J. (2000). Ventricular fibrillation: mechanisms of initiation and maintenance. Annu Rev Physiol, 62, pp. 25-50.

Janse, M. J. (2004). Electrophysiological changes in heart failure and their relationship to arrhythmogenesis. Cardiovasc Res, 61(2), pp. 208-217.

Janse, M. J., Coronel, R., Wilms-Schopman, F. J., \& de Groot, J. R. (2003). Mechanical effects on arrhythmogenesis: from pipette to patient. Prog Biophys Mol Biol, 82(1-3), pp. 187-195.

Janse, M. J., \& Wit, A. L. (1989). Electrophysiological mechanisms of ventricular arrhythmias resulting from myocardial ischemia and infarction. Physiol Rev, 69(4), pp. 1049-1169.

Kamkin, A., Kiseleva, I., \& Isenberg, G. (2000a). Stretch-activated currents in ventricular myocytes: amplitude and arrhythmogenic effects increase with hypertrophy. Cardiovasc Res, 48(3), pp. 409-420.

Kamkin, A., Kiseleva, I., Isenberg, G., Wagner, K. D., Gunther, J., Theres, H., et al. (2003). Cardiac fibroblasts and the mechano-electric feedback mechanism in healthy and diseased hearts. Prog Biophys Mol Biol, 82(1-3), pp. 111-120.

Kamkin, A., Kiseleva, I., Wagner, K. D., Leiterer, K. P., Theres, H., Scholz, H., et al. (2000b). Mechano-electric feedback in right atrium after left ventricular infarction in rats. $J$ Mol Cell Cardiol, 32(3), pp. 465-477.

Kaprielian, R. R., Dupont, E., Hafizi, S., Poole-Wilson, P. A., Khaghani, A., Yacoub, M. H., et al. (1997). Angiotensin II receptor type $1 \mathrm{mRNA}$ is upregulated in atria of patients with end-stage heart failure. J Mol Cell Cardiol, 29(8), pp. 2299-2304.

Kass, R. S., \& Tsien, R. W. (1982). Fluctuations in membrane current driven by intracellular calcium in cardiac Purkinje fibers. Biophys J, 38(3), pp. 259-269.

Kass, R. S., Tsien, R. W., \& Weingart, R. (1978). Ionic basis of transient inward current induced by strophanthidin in cardiac Purkinje fibres. J Physiol, 281, pp. 209-226.

Kiyonaka, S., Kato, K., Nishida, M., Mio, K., Numaga, T., Sawaguchi, Y., et al. (2009). Selective and direct inhibition of TRPC 3 channels underlies biological activities of a pyrazole compound. Proc Natl Acad Sci U S A, 106(13), pp. 5400-5405.

Komuro, I., \& Yazaki, Y. (1993). Control of cardiac gene expression by mechanical stress. Annu Rev Physiol, 55, pp. 55-75.

Kroemer, G., Galluzzi, L., \& Brenner, C. (2007). Mitochondrial membrane permeabilization in cell death. Physiol Rev, 87(1), pp. 99-163.

Kruse, M., Schulze-Bahr, E., Corfield, V., Beckmann, A., Stallmeyer, B., Kurtbay, G., et al. (2009). Impaired endocytosis of the ion channel TRPM4 is associated with human progressive familial heart block type I. J Clin Invest, 119(9), pp. 2737-2744. 
Kuwahara, K., Wang, Y., McAnally, J., Richardson, J. A., Bassel-Duby, R., Hill, J. A., et al. (2006). TRPC6 fulfills a calcineurin signaling circuit during pathologic cardiac remodeling. J Clin Invest, 116(12), pp. 3114-3126.

Kuzmin, A. I., Lakomkin, V. L., Kapelko, V. I., \& Vassort, G. (1998). Interstitial ATP level and degradation in control and postmyocardial infarcted rats. Am J Physiol, 275(3 Pt 1), pp. C766-771.

Laflamme, M. A., \& Becker, P. L. (1996). Ca2+-induced current oscillations in rabbit ventricular myocytes. Circ Res, 78(4), pp. 707-716.

Langley, B., \& Ratan, R. R. (2004). Oxidative stress-induced death in the nervous system: cell cycle dependent or independent? J Neurosci Res, 77(5), pp. 621-629.

Launay, P., Fleig, A., Perraud, A. L., Scharenberg, A. M., Penner, R., \& Kinet, J. P. (2002). TRPM4 is a Ca2+-activated nonselective cation channel mediating cell membrane depolarization. Cell, 109(3), pp. 397-407.

Lederer, W. J., \& Tsien, R. W. (1976). Transient inward current underlying arrhythmogenic effects of cardiotonic steroids in Purkinje fibres. J Physiol, 263(2), pp. 73-100.

Li, M., Du, J., Jiang, J., Ratzan, W., Su, L. T., Runnels, L. W., et al. (2007). Molecular determinants of $\mathrm{Mg} 2+$ and $\mathrm{Ca} 2+$ permeability and $\mathrm{pH}$ sensitivity in TRPM6 and TRPM7. J Biol Chem, 282(35), pp. 25817-25830.

Li, M., Jiang, J., \& Yue, L. (2006). Functional characterization of homo- and heteromeric channel kinases TRPM6 and TRPM7. J Gen Physiol, 127(5), pp. 525-537.

Liu, H., El Zein, L., Kruse, M., Guinamard, R., Beckmann, A., Bozio, A., et al. (2010). Gain-offunction mutations in TRPM4 cause autosomal dominant isolated cardiac conduction disease. Circ Cardiovasc Genet, 3(4), pp. 374-385.

Maroto, R., Raso, A., Wood, T. G., Kurosky, A., Martinac, B., \& Hamill, O. P. (2005). TRPC1 forms the stretch-activated cation channel in vertebrate cells. Nat Cell Biol, 7(2), pp. 179-185.

Mathar, I., Vennekens, R., Meissner, M., Kees, F., Van der Mieren, G., Camacho Londono, J. E., et al. (2010). Increased catecholamine secretion contributes to hypertension in TRPM4-deficient mice. J Clin Invest, 120(9), pp. 3267-3279.

Mederos y Schnitzler, M., Storch, U., Meibers, S., Nurwakagari, P., Breit, A., Essin, K., et al. (2008). Gq-coupled receptors as mechanosensors mediating myogenic vasoconstriction. Embo J, 27(23), pp. 3092-3103.

Miller, B. A., \& Zhang, W. (2010). TRP channels as mediators of oxidative stress. Adv Exp Med Biol, 704, pp. 531-544.

Misra, M. K., Sarwat, M., Bhakuni, P., Tuteja, R., \& Tuteja, N. (2009). Oxidative stress and ischemic myocardial syndromes. Med Sci Monit, 15(10), pp. RA209-219.

Morita, H., Honda, A., Inoue, R., Ito, Y., Abe, K., Nelson, M. T., et al. (2007). Membrane stretch-induced activation of a TRPM4-like nonselective cation channel in cerebral artery myocytes. J Pharmacol Sci, 103(4), pp. 417-426.

Nattel, S., Maguy, A., Le Bouter, S., \& Yeh, Y. H. (2007). Arrhythmogenic ion-channel remodeling in the heart: heart failure, myocardial infarction, and atrial fibrillation. Physiol Rev, 87(2), pp. 425-456.

Naylor, J., Al-Shawaf, E., McKeown, L., Manna, P. T., Porter, K. E., O'Regan, D., et al. (2011). TRPC5 channel sensitivities to antioxidants and hydroxylated stilbenes. J Biol Chem, 286(7), pp. 5078-5086. 
Nilius, B., Prenen, J., Voets, T., \& Droogmans, G. (2004). Intracellular nucleotides and polyamines inhibit the Ca2+-activated cation channel TRPM4b. Pflugers Arch, 448(1), pp. 70-75.

Nilius, B., \& Vennekens, R. (2006). From cardiac cation channels to the molecular dissection of the transient receptor potential channel TRPM4. Pflugers Arch, 453(3), pp. 313321.

Nishida, M., \& Kurose, H. (2008). Roles of TRP channels in the development of cardiac hypertrophy. Naunyn Schmiedebergs Arch Pharmacol, 378(4), pp. 395-406.

Nishida, M., Onohara, N., Sato, Y., Suda, R., Ogushi, M., Tanabe, S., et al. (2007). Galpha12/13-mediated up-regulation of TRPC6 negatively regulates endothelin-1induced cardiac myofibroblast formation and collagen synthesis through nuclear factor of activated T cells activation. J Biol Chem, 282(32), pp. 23117-23128.

Ohba, T., Watanabe, H., Murakami, M., Takahashi, Y., Iino, K., Kuromitsu, S., et al. (2007). Upregulation of TRPC1 in the development of cardiac hypertrophy. J Mol Cell Cardiol, 42(3), pp. 498-507.

Olson, T. M., Michels, V. V., Ballew, J. D., Reyna, S. P., Karst, M. L., Herron, K. J., et al. (2005). Sodium channel mutations and susceptibility to heart failure and atrial fibrillation. Jama, 293(4), pp. 447-454.

Onohara, N., Nishida, M., Inoue, R., Kobayashi, H., Sumimoto, H., Sato, Y., et al. (2006). TRPC3 and TRPC6 are essential for angiotensin II-induced cardiac hypertrophy. Embo J, 25(22), pp. 5305-5316.

Osadchii, O. E. (2010). Mechanisms of hypokalemia-induced ventricular arrhythmogenicity. Fundam Clin Pharmacol, 24(5), pp. 547-559.

Poteser M, Graziani A, Rosker C, Eder P, Derler I, Kahr H, Zhu MX, Romanin C, Groschner K (2006). TRPC3 and TRPC4 associate to form a redox-sensitive cation channel. Evidence for expression of native TRPC3-TRPC4 heteromeric channels in endothelial cells. J Biol Chem, 12;281(19), pp.13588-95.

Pogwizd, S. M. (2003). Clinical potential of sodium-calcium exchanger inhibitors as antiarrhythmic agents. Drugs, 63(5), pp. 439-452.

Pogwizd, S. M., \& Bers, D. M. (2004). Cellular basis of triggered arrhythmias in heart failure. Trends Cardiovasc Med, 14(2), pp. 61-66.

Pogwizd, S. M., Schlotthauer, K., Li, L., Yuan, W., \& Bers, D. M. (2001). Arrhythmogenesis and contractile dysfunction in heart failure: Roles of sodium-calcium exchange, inward rectifier potassium current, and residual beta-adrenergic responsiveness. Circ Res, 88(11), pp. 1159-1167.

Ravens, U. Antiarrhythmic therapy in atrial fibrillation. (2010). Pharmacol Ther, 128(1), pp. 129-145.

Ravens, U. Novel pharmacological approaches for antiarrhythmic therapy. (2010). Naunyn Schmiedebergs Arch Pharmacol, 381(3), pp. 187-193.

Ravens, U. (2003). Mechano-electric feedback and arrhythmias. Prog Biophys Mol Biol, 82(13), pp. 255-266.

Roberts, J. D., \& Gollob, M. H. (2010). The genetic and clinical features of cardiac channelopathies. Future Cardiol, 6(4), pp. 491-506.

Roden, D. M. (2004). Drug-induced prolongation of the QT interval. N Engl J Med, 350(10), pp. 1013-1022. 
Sack, M. N., Smith, R. M., \& Opie, L. H. (2000). Tumor necrosis factor in myocardial hypertrophy and ischaemia--an anti-apoptotic perspective. Cardiovasc Res, 45(3), pp. 688-695.

Saenen, J. B., \& Vrints, C. J. (2008). Molecular aspects of the congenital and acquired Long QT Syndrome: clinical implications. J Mol Cell Cardiol, 44(4), pp. 633-646.

Satoh, S., Tanaka, H., Ueda, Y., Oyama, J., Sugano, M., Sumimoto, H., et al. (2007). Transient receptor potential (TRP) protein 7 acts as a $\mathrm{G}$ protein-activated $\mathrm{Ca}^{2+}$ channel mediating angiotensin II-induced myocardial apoptosis. Mol Cell Biochem, 294(1-2), pp. 205-215.

Schott, J. J., Alshinawi, C., Kyndt, F., Probst, V., Hoorntje, T. M., Hulsbeek, M., et al. (1999). Cardiac conduction defects associate with mutations in SCN5A. Nat Genet, 23(1), pp. 20-21.

Seth, M., Sumbilla, C., Mullen, S. P., Lewis, D., Klein, M. G., Hussain, A., et al. (2004). Sarco(endo)plasmic reticulum Ca2+ ATPase (SERCA) gene silencing and remodeling of the Ca2+ signaling mechanism in cardiac myocytes. Proc Natl Acad Sci U S A, 101(47), pp. 16683-16688.

Shan, D., Marchase, R. B., \& Chatham, J. C. (2008). Overexpression of TRPC3 increases apoptosis but not necrosis in response to ischemia-reperfusion in adult mouse cardiomyocytes. Am J Physiol Cell Physiol, 294(3), pp. C833-841.

Siemen, D. (1993). Nonselective cation channels. Exs, 66, pp. 3-25.

Sipido, K. R., Bito, V., Antoons, G., Volders, P. G., \& Vos, M. A. (2007). Na/Ca exchange and cardiac ventricular arrhythmias. Ann N Y Acad Sci, 1099, pp. 339-348.

Song, Y., \& Belardinelli, L. (1994). ATP promotes development of afterdepolarizations and triggered activity in cardiac myocytes. Am J Physiol, 267(5 Pt 2), pp. H20052011.

Souders, C. A., Bowers, S. L., \& Baudino, T. A. (2009). Cardiac fibroblast: the renaissance cell. Circ Res, 105(12), pp. 1164-1176.

Spassova, M. A., Hewavitharana, T., Xu, W., Soboloff, J., \& Gill, D. L. (2006). A common mechanism underlies stretch activation and receptor activation of TRPC6 channels. Proc Natl Acad Sci U S A, 103(44), pp. 16586-16591.

Stacy, G. P., Jr., Jobe, R. L., Taylor, L. K., \& Hansen, D. E. (1992). Stretch-induced depolarizations as a trigger of arrhythmias in isolated canine left ventricles. Am J Physiol, 263(2 Pt 2), pp. H613-621.

Suchyna, T. M., Johnson, J. H., Hamer, K., Leykam, J. F., Gage, D. A., Clemo, H. F., et al. (2000). Identification of a peptide toxin from Grammostola spatulata spider venom that blocks cation-selective stretch-activated channels. J Gen Physiol, 115(5), pp. 583598.

Swynghedauw, B. (1999). Molecular mechanisms of myocardial remodeling. Physiol Rev, 79(1), pp. 215-262.

Szallasi, A., Cortright, D. N., Blum, C. A., \& Eid, S. R. (2007). The vanilloid receptor TRPV1: 10 years from channel cloning to antagonist proof-of-concept. Nat Rev Drug Discov, 6(5), pp. 357-372.

Takahashi, N., Kozai, D., Kobayashi, R., Ebert, M., \& Mori, Y. (2011). Roles of TRPM2 in oxidative stress. Cell Calcium, pp. 
Ter Keurs, H. E., \& Boyden, P. A. (2007). Calcium and arrhythmogenesis. Physiol Rev, 87(2), pp. 457-506.

Towbin, J. A., \& Vatta, M. (2001). Molecular biology and the prolonged QT syndromes. Am J Med, 110(5), pp. 385-398.

Tsai, E. J., \& Kass, D. A. (2009). Cyclic GMP signaling in cardiovascular pathophysiology and therapeutics. Pharmacol Ther, 122(3), pp. 216-238.

Vassort, G., Bideaux, P., \& Alvarez, J. (2010). Could early ischemic arrhythmia triggered by purinergic activation of the transient receptor potential channels be prevented by creatine? Exp Clin Cardiol, 15(4), pp. e104-108.

Vay, L., Gu, C., \& McNaughton, P. A. (2011). The thermo-TRP ion channel family: properties and therapeutic implications. Br J Pharmacol, pp.

Venetucci, L. A., Trafford, A. W., O'Neill, S. C., \& Eisner, D. A. (2008). The sarcoplasmic reticulum and arrhythmogenic calcium release. Cardiovasc Res, 77(2), pp. 285292.

Ward, M. L., Williams, I. A., Chu, Y., Cooper, P. J., Ju, Y. K., \& Allen, D. G. (2008). Stretchactivated channels in the heart: contributions to length-dependence and to cardiomyopathy. Prog Biophys Mol Biol, 97(2-3), pp. 232-249.

Watanabe, H., Murakami, M., Ohba, T., Takahashi, Y., \& Ito, H. (2008). TRP channel and cardiovascular disease. Pharmacol Ther, 118(3), pp. 337-351.

Wehrens, X. H., Lehnart, S. E., Huang, F., Vest, J. A., Reiken, S. R., Mohler, P. J., et al. (2003). FKBP12.6 deficiency and defective calcium release channel (ryanodine receptor) function linked to exercise-induced sudden cardiac death. Cell, 113(7), pp. 829-840.

Wijffels, M. C., Kirchhof, C. J., Dorland, R., \& Allessie, M. A. (1995). Atrial fibrillation begets atrial fibrillation. A study in awake chronically instrumented goats. Circulation, 92(7), pp. 1954-1968.

Wu, L. J., Sweet, T. B., \& Clapham, D. E. (2010). International Union of Basic and Clinical Pharmacology. LXXVI. Current progress in the mammalian TRP ion channel family. Pharmacol Rev, 62(3), pp. 381-404.

Wu, Y., \& Anderson, M. E. (2000). Ca ${ }^{2+}$-activated non-selective cation current in rabbit ventricular myocytes. J Physiol, 522 Pt 1, pp. 51-57.

Yamamoto, S., Shimizu, S., Kiyonaka, S., Takahashi, N., Wajima, T., Hara, Y., et al. (2008). TRPM2-mediated Ca2+influx induces chemokine production in monocytes that aggravates inflammatory neutrophil infiltration. Nat Med, 14(7), pp. 738-747.

Yang, K. T., Chang, W. L., Yang, P. C., Chien, C. L., Lai, M. S., Su, M. J., et al. (2006). Activation of the transient receptor potential M2 channel and poly(ADP-ribose) polymerase is involved in oxidative stress-induced cardiomyocyte death. Cell Death Differ, 13(10), pp. 1815-1826.

Yasuda, N., Miura, S., Akazawa, H., Tanaka, T., Qin, Y., Kiya, Y., et al. (2008). Conformational switch of angiotensin II type 1 receptor underlying mechanical stress-induced activation. EMBO Rep, 9(2), pp. 179-186.

Yu, Y., Sweeney, M., Zhang, S., Platoshyn, O., Landsberg, J., Rothman, A., et al. (2003). PDGF stimulates pulmonary vascular smooth muscle cell proliferation by upregulating TRPC6 expression. Am J Physiol Cell Physiol, 284(2), pp. C316-330. 
Yue, L., Xie, J., \& Nattel, S. Molecular determinants of cardiac fibroblast electrical function and therapeutic implications for atrial fibrillation. (2011). Cardiovasc Res, 89(4), pp. 744-753.

Zareba, W., Moss, A. J., Locati, E. H., Lehmann, M. H., Peterson, D. R., Hall, W. J., et al. (2003). Modulating effects of age and gender on the clinical course of long QT syndrome by genotype. J Am Coll Cardiol, 42(1), pp. 103-109.

Zhu, J., Liu, M., Kennedy, R. H., \& Liu, S. J. (2006). TNF-alpha-induced impairment of mitochondrial integrity and apoptosis mediated by caspase- 8 in adult ventricular myocytes. Cytokine, 34(1-2), pp. 96-105.

Zima, A. V., \& Blatter, L. A. (2006). Redox regulation of cardiac calcium channels and transporters. Cardiovasc Res, 71(2), pp. 310-321. 


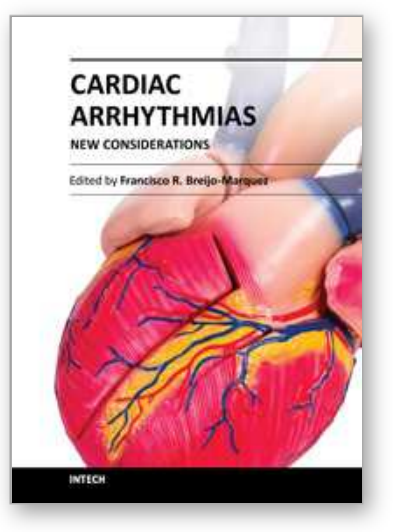

\author{
Cardiac Arrhythmias - New Considerations \\ Edited by Prof. Francisco R. Breijo-Marquez
}

ISBN 978-953-51-0126-0

Hard cover, 534 pages

Publisher InTech

Published online 29, February, 2012

Published in print edition February, 2012

The most intimate mechanisms of cardiac arrhythmias are still quite unknown to scientists. Genetic studies on ionic alterations, the electrocardiographic features of cardiac rhythm and an arsenal of diagnostic tests have done more in the last five years than in all the history of cardiology. Similarly, therapy to prevent or cure such diseases is growing rapidly day by day. In this book the reader will be able to see with brighter light some of these intimate mechanisms of production, as well as cutting-edge therapies to date. Genetic studies, electrophysiological and electrocardiographyc features, ion channel alterations, heart diseases still unknown , and even the relationship between the psychic sphere and the heart have been exposed in this book. It deserves to be read!

\title{
How to reference
}

In order to correctly reference this scholarly work, feel free to copy and paste the following:

Ryuji Inoue, Duan Yubin, Hu Yaopeng and Jun Ichikawa (2012). The Pathophysiological Implications of TRP Channels in Cardiac Arrhythmia, Cardiac Arrhythmias - New Considerations, Prof. Francisco R. BreijoMarquez (Ed.), ISBN: 978-953-51-0126-0, InTech, Available from: http://www.intechopen.com/books/cardiacarrhythmias-new-considerations/the-pathophysiological-implications-of-trp-channels-in-cardiac-arrhythmia

\section{INTECH}

open science | open minds

\section{InTech Europe}

University Campus STeP Ri

Slavka Krautzeka 83/A

51000 Rijeka, Croatia

Phone: +385 (51) 770447

Fax: +385 (51) 686166

www.intechopen.com

\section{InTech China}

Unit 405, Office Block, Hotel Equatorial Shanghai

No.65, Yan An Road (West), Shanghai, 200040, China

中国上海市延安西路65号上海国际贵都大饭店办公楼405单元

Phone: +86-21-62489820

Fax: +86-21-62489821 
(C) 2012 The Author(s). Licensee IntechOpen. This is an open access article distributed under the terms of the Creative Commons Attribution 3.0 License, which permits unrestricted use, distribution, and reproduction in any medium, provided the original work is properly cited. 